\title{
BETTERGEOEDU: THE USE OF MINECRAFT AS AN INTERACTIVE TOOL TO FACILITATE THE KNOWLEDGE ON ROCKS AND MINERALS IN PRIMARY SCHOOL STUDENTS
}

\author{
J.L. Costafreda Mustelier(1); C. Peña Narciso(1); J. Herrera Herbert ${ }^{(1)}$; \\ P. Westrin(2); F.P. Luque(3); L. Piovano(3) \\ (1) Universidad Politécnica de Madrid - Technical University of Madrid. Escuela Técnica \\ Superior de Ingenieros de Minas y Energía - Higher Technical School of Mining and Energy \\ Engineering (SPAIN) \\ (2) Sveriges Geologiska Undersökning - Geological Survey of Sweden (SWEDEN) \\ (3) Universidad Politécnica de Madrid - Technical University of Madrid. Centro de Domótica \\ Integral - Research Centre for Smart Buildings and Energy Efficiency (SPAIN)
}

\begin{abstract}
The use of games as learning tools has become a valuable way to help students to learn while having fun. Based on this idea, BetterGeo is a modification created by the Geological Survey of Sweden (SGU) on Minecraft, one of the most popular games in the world, to improve to help primary school students to get familiarised with the importance of raw materials in modern life and start learning basic concepts on geology, minerals, mining, mineral processing, and circular economy.
\end{abstract}

Together with the development of the mod, BetterGeo projects also work in the development of learning materials to help teachers and students in this approach to the Raw Materials sector.

The project developing this initiative, named BetterGeoEdu, is developed with the support of EIT Raw Materials, one of the eight Knowledge and Innovation Communities (KICs) initiated by the EIT (European Institute of Innovation and Technology), funded by the European Commission, and whose mission is to help boost the competitiveness, growth, and attractiveness of the European raw materials sector through radical innovation and guided entrepreneurship. The Technical University of Madrid is one of the partners participating in this pioneering initiative, and in this paper, the idea behind BetterGeo, the goals, and the partners of the consortium are described together with the innovative development of exercises and educational material designed to make easy to primary school students the first contact with raw materials.

One of the exercises, which is described in this paper, is a new, fast, simple, and efficient learning tool on rocks and minerals, in the form of an interactive game complementing BetterGeo. It is designed for pre-university level students, with or without a vocation for natural sciences. With the support of four sample boxes containing igneous, metamorphic, sedimentary, and mineral rocks for the exercise, the student randomly chooses a sample and starts the game. The game raises several questions about the sample that the student must answer intuitively with a click. If the answer is affirmative, the system offers a route with more information about the sample. If the answer is negative, the system forces the student to go back and start again. If the students can complete the exercise, they will have access to the name of the rock or mineral and will be able to access the sample boxes to start a new analysis. The commands are interactive and intuitive, to better capture the student's attention.

This system offers several advantages: the student manages the entire process by himself, learns without prior knowledge, understands instantly the meaning of the questions and answers as they arise based on comparison with objects and situations known to the student. Additionally, it teaches the applications and uses of minerals and rocks in everyday life.

Keywords: Gaming, learning, interactive, raw materials, rocks, and minerals, student, uses

\section{INTRODUCTION}

Nowadays, there has been an almost radical change in teaching techniques [1, 2, 3, 4].. As happened with the arrival of Covid-19, society has been forced to create new systems to transmit education $[5,6$, $7,8,9,10]$. These systems are developed within an interactive scenario, not face-to-face, but equally 
effective, comfortable, and simultaneous [11]. The advance of the pandemic has made that practically all countries, proportionally, have opted for "tale teaching" (distance learning), thus marking a starting point for the adaptation and potential use of Information and Communication Technologies (ICT).

At the same time, the European Union is committed to the development and sustainable use of raw materials [12, 13]. "The European Green Deal" document [14] provides an action plan to boost the efficient use of resources by moving to a clean, circular economy, restore biodiversity and cut pollution. To become more competitive as it becomes greener and more circular, the industry will need a secure supply of clean and affordable energy and raw materials. Ensuring the supply of sustainable raw materials by diversifying supply from both primary and secondary sources, is therefore one of the prerequisites to make this transition happen. This involves instilling in society the knowledge of the resources available in the European territory and in the rest of the world, what they are used for and what products of daily life exist thanks to them, as well as instilling also the certainty that their existence is finite and limited, so the exploitation of them must be responsible.

The use of games as learning tools has become a valuable way to help students to learn while having fun. Based on this idea, BetterGeo is a modification created by the Geological Survey of Sweden (SGU) on Minecraft, one of the most popular games in the world, to improve to help primary school students to get familiarised with the importance of raw materials in modern life and start learning basic concepts on geology, minerals, mining, mineral processing, and circular economy.

Together with the development of the mod, BetterGeo projects also work in the development of learning materials to help teachers and students in this approach to the Raw Materials sector [15].

The project developing this initiative, named BetterGeoEdu, has the active support of EIT Raw Materials. EIT Raw Materials is one of the eight Knowledge and Innovation Communities created to boost innovation and entrepreneurship across Europe with the support of the European Institute of Innovation and Technology (EIT). Created in 2015 and participated by more than 120 European partners from leading industries, universities, and research institutions from more than 20 EU countries [16], EIT Raw Materials is the largest consortium in the raw materials sector worldwide. Its partners are active across the entire raw materials value chain, from sustainable exploration, efficient mining, and mineral processing to substitution, recycling, and circular economy. It has the vision of developing raw materials into a major strength for Europe by finding new, innovative solutions to secure supply and improve the raw materials sector in Europe and the mission of contributing to boosting competitiveness, growth, and attractiveness of the European raw materials sector via radical innovation, new educational approaches and guided entrepreneurship [17].

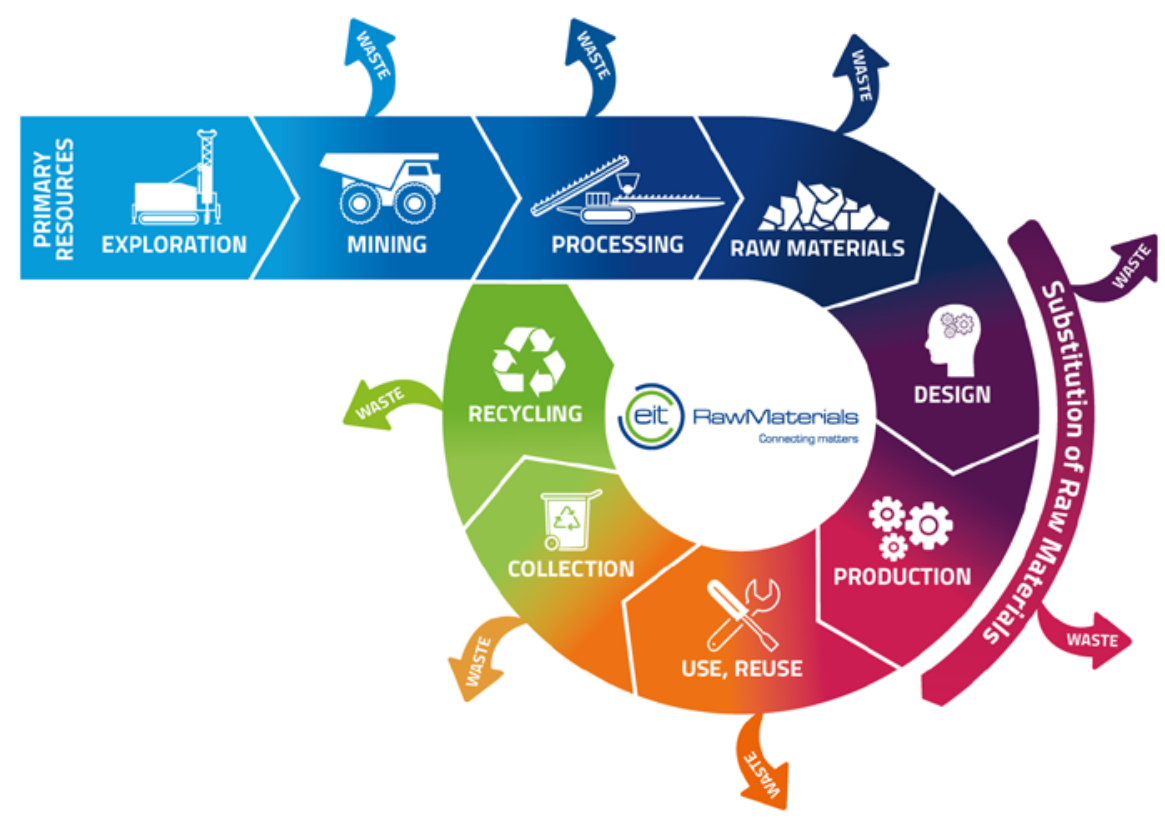

Figure 1. EIT Raw Materials Circular Economy Concept. (https://eitrawmaterials.eu, 2018) 
The Raw Materials Academy is the overarching brand of all the educational activities of the EIT Raw Materials. Activities across the entire ecosystem of learners (Ph.D. students, masters' students, industrial partners, professionals within the raw materials sector, and wider society) foster new ways of learning and teaching by connecting academia, industry, and research organizations. EIT Raw Materials will educate people that will have an intra- and entrepreneurial mindset and will be able to develop their functions in new working environments, fostering the entrepreneurial and innovation skills, knowledge, and attitudes needed for the entre- and intrapreneurs of tomorrow.

This project is being developed by a consortium coordinated by Geological Survey of Sweden, SGU (Sweden), and constituted together by the following partners: Consiglio Nazionale delle Ricerche CNR (Italy), Geological Survey of Slovenia - GeoZS (Eslovenia), Montanuniversität Leoben (Austria), Tallinn University of Technology (Estonia), Trinity College Dublin (Ireland), Universidad Politecnica de Madrid - UPM or Technical University of Madrid (Spain), Université de Liège (Belgium), University of Limerick (Ireland), Turvallisuus- ja kemikaalivirasto - Tukes (Finland)

In this paper, the idea behind BetterGeo, the goals, and the partners of the consortium are described together with the innovative development of exercises and educational material designed to make it easy for primary school students the first contact with raw materials.

\section{METHODOLOGY}

Games are powerful tools to increase learning potential. Learning while having fun helps students retain knowledge better because the process is more enjoyable and memorable. Minecraft is one of the most popular games in the world (there are millions of people who play it every day). Because so many people are familiar with Minecraft, it becomes a great tool to use for learning. BetterGeo Education is made to teach about raw materials, circular economy, sustainability, and more. The tool introduces several new features and tools to enhance learning [18].

BetterGeo is a modification (mod, in short) for Minecraft created by the Geological Survey of Sweden (SGU). BetterGeo brings more realistic geology to the game, with additional rocks, soils, raw materials, tools, items, and more. The mod teaches about raw materials and their importance in modern society. Moreover, the mod offers new opportunities for the player thanks to more realistic blocks and features as well as new items from daily life to craft. Together with this, BetterGeo is available for free to download.

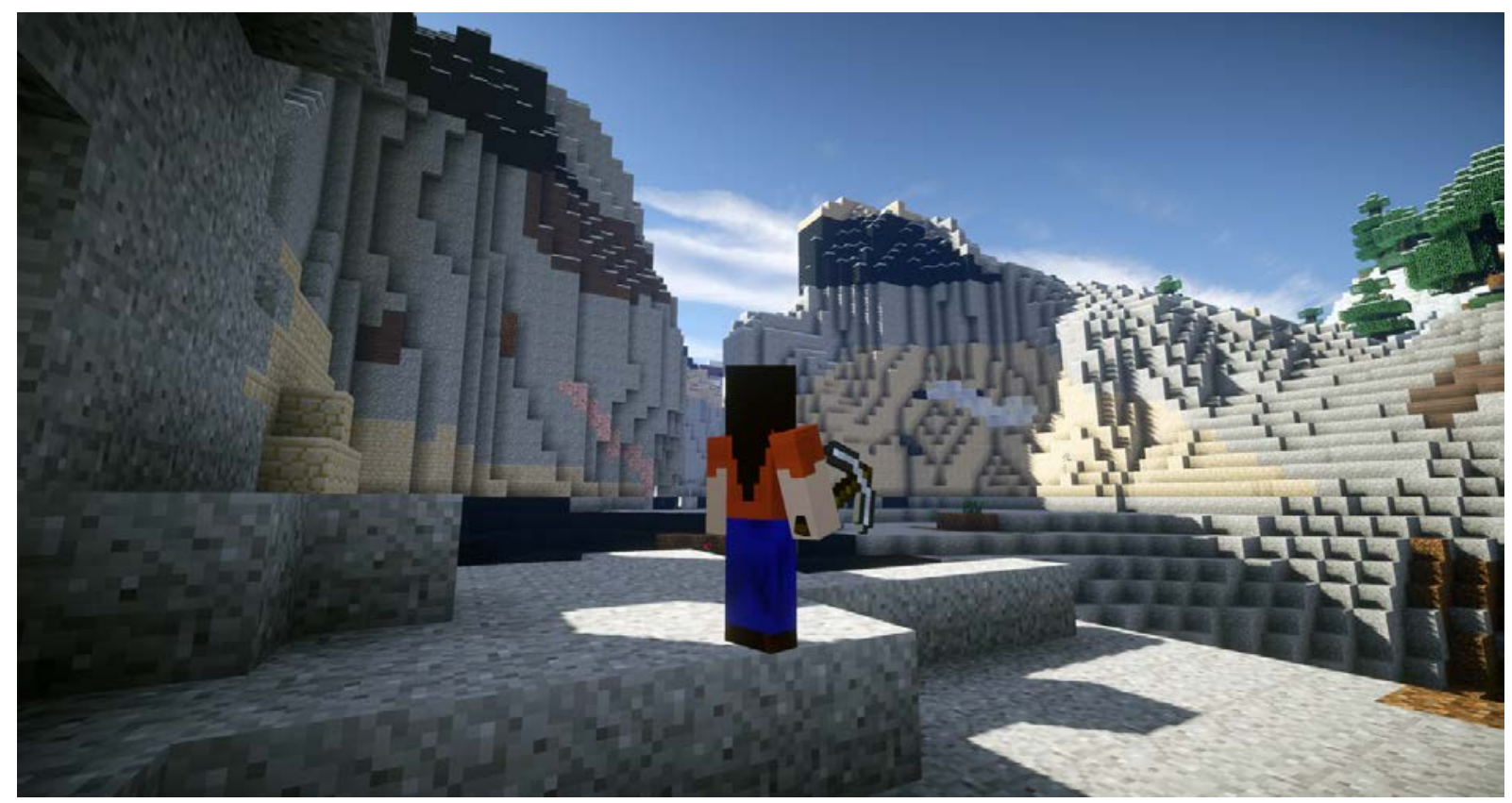

Figure 2. Image of the game. (https://www.bettergeoedu.com, 2020) 
BetterGeoEdu (Edu for Education) is an additional tool for teachers to use in the classroom . It provides several different exercises to use in the classroom, complemented with teacher instructions, tips, and tricks as well as extra educational material, all free to use by teachers, students, parents, etc., as it can be used both in the classroom and at home, as the exercises can be used with or without computers. BetterGeoEdu provides simple step-by-step instructions on how to teach with Minecraft and BetterGeo about the different raw materials we need for everyday life, where we can find them, and how to extract them using sustainable methods [18].

All the exercises have been developed by the members of the consortium and are aimed primarily at primary school students. This document explains an exercise developed by Universidad Politécnica de Madrid (Technical University of Madrid) as a procedure that students must follow to proceed to describe minerals and rocks [19], even without having prior knowledge of these materials. At the same time, it is intended that they develop the ability to deduce, intuitively, its use, and its applications in different fields of modern society.

The procedure has two modalities: a) mineral recognition and b) rock recognition. Mineral and rock samples appear in virtual sample boxes (Figure 3). The fundamental characteristics that define minerals are color, shape, brightness, hardness, transparency, brittleness, malleability, ductility, elasticity, magnetism, among other properties [20]. The natural conditions in which minerals and rocks were formed must also be known, considering factors such as pressure and temperature [21]. With this exercise, the student will work with some of the basic properties of minerals and rocks above mentioned.

\subsection{Example 1. Methodology for the recognition of minerals interactively}

The student clicks on the Minerals Sample Box. With this gesture, the virtual box opens on the screen and various mineral samples appear. The student can then freely choose any of the mineral samples arranged in the box; For example, suppose the student clicks on sample 1.

With this action, an image of the sample [22] appears on screen (as shown in Figure 3), together with a series of commands with specific instructions that the student must follow. Each instruction is an activity to be developed.

\section{Activity 1: "Select the sample by clicking on it"}

Activity 2: "What color is this mineral?" Describe the color and shades of the mineral. If the description is correct, a command appears offering the user more information on the colors and shades. If the information introduced is wrong, the student must start over again. The student cannot access activity 3 until activity 2 has been completed.

Activity 3: "What shape is this mineral?" The command instructs the student to describe the shape of the mineral, that is, if it has geometry, if it has well-defined faces, or if it is irregular. The correct answer activates a new option, where the student can expand a sub-screen where the student can learn additional information about the activity carried out. A wrong answer obliges the student to start over again. Access to activity 4 is not permitted until activity 3 has been completed.

Activity 4: "How shiny is this mineral?". This activity instructs the student to describe the shine of the mineral. You must answer if it is metallic, like metals, or if on the contrary, it is non-metallic, like most objects that are not metallic. The correct answer opens a path that provides the student with an extended explanation about the brightness of the sample. The wrong answer forces the student to back again. Once again, access activity 5 will not appear until activity 4 has been completed.

Activity 5: Do you think this mineral is hard? The command poses a question to the student about the hardness of the mineral. A correct answer gives the possibility of increasing the knowledge about the hardness of the mineral, comparing it with minerals that are harder or less hard than the sample under study. If the student chooses the wrong option, they have to start over. You cannot access activity 6 until activity 5 has been completed.

Activity 6: "How was this mineral formed?" In this activity, the student chooses one of the answers to the question of how the mineral was formed in nature: low, medium, or high temperature. The appropriate answer activates an option with more explanation about it. The wrong answer forces the student to return to the beginning of this activity. As in previous activities, access to activity 7 will not open until activity 6 has been completed successfully. 


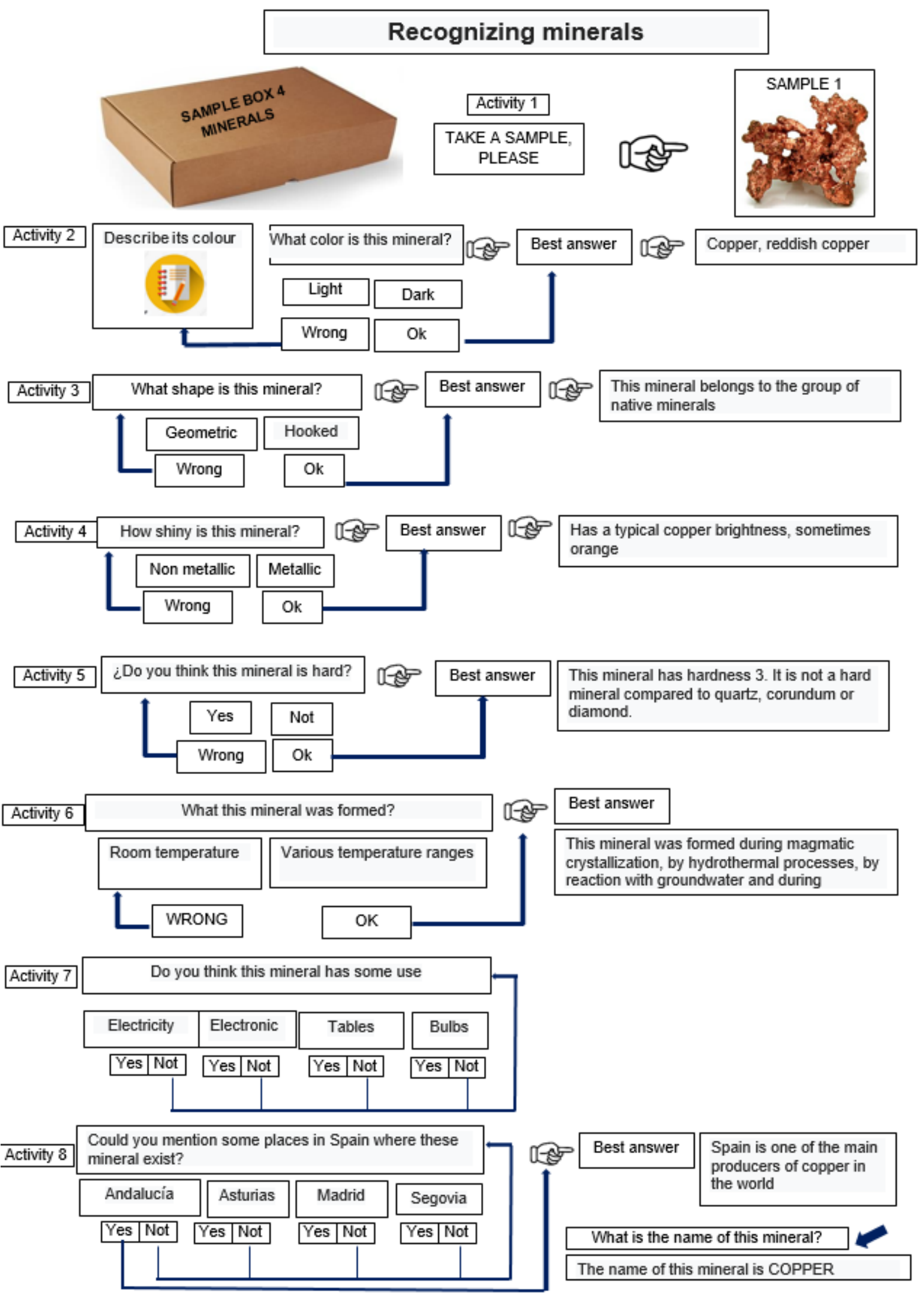

Figure 3. Methodology for the interactive recognition of minerals. Proposed diagram for the mineral recognition learning process for elementary school students. 
Activity 7: Do you think this mineral has any use? In this activity, the student is asked about the use of the mineral being studied. Various commands are displayed on the screen (four in total), and each one has two additional subcommands that show to the student correct or incorrect possibilities. If the student chooses at least two wrong answers, s/he will be returned to the beginning of activity 7. If all the answers are correct, access to activity 8 is opened.

Activity 8: "Can you mention any place in Spain where this mineral can be found?" With this activity, the student must learn where the deposits of the mineral studied are located in Spain (for other countries, the corresponding versions will be prepared). Four commands open on-screen indicating four regions. Two of those regions are wrong and two are correct. Choosing the wrong regions requires starting again activity 8 . The correct answers allow accessing a screen where the student can learn additional information and expanded his/her knowledge. Simultaneously, the student accesses a space where the name of the mineral is shown.

Once all the activities have been completed, the student can click on the command "I WANT TO KNOW MORE ABOUT THE USE OF THIS MINERAL". This option allows the student to access the different uses and applications of this mineral $[23,24,25]$ through images (see figure 4).

\section{WANT TO KNOW MORE ABOUT THE USE OF THIS MINERAL}

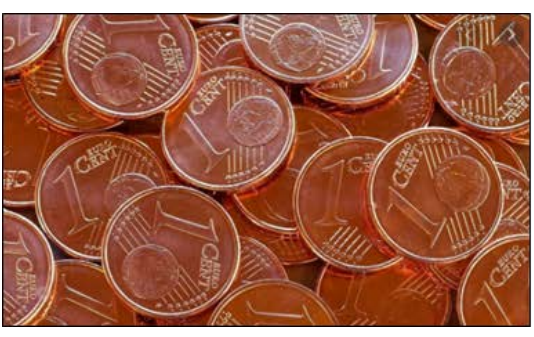

a

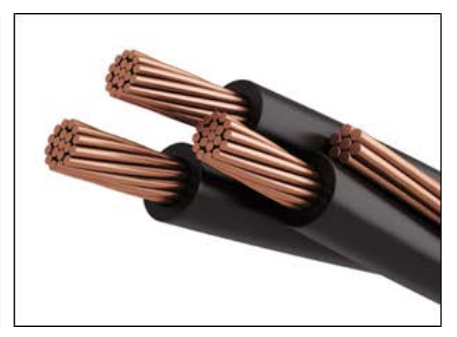

$b$

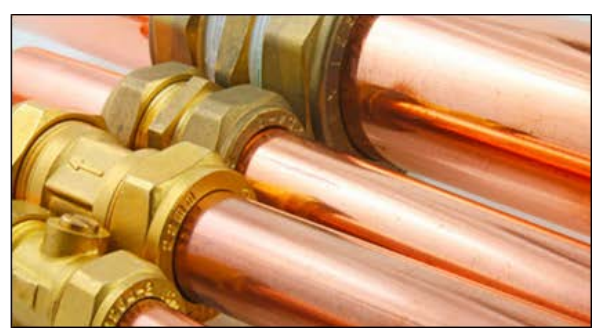

C

Figure 4. Graphic examples of the use and applications of minerals: a) coins [23]; b) electricity [24]; c) pipelines [25].

\subsection{Example 2. Methodology for rock recognition}

The fundamental characteristics that define rocks are color, crystallinity, hardness, texture, and structure, among other properties [26]. Like minerals, the formation conditions, pressure, temperature, and the alterations that affect them must be determined. Through this exercise, it is intended that the student be able to distinguish between minerals and rock, using very simple questions. The exercise ends with the identification of the name of the rock.

The student clicks on the Rocks Sample Box. On the screen, the box will open, and different rock samples will appear. The student must freely click on any rock sample, which will display the image of the sample, as well as the commands available for the development of activities (see figure 5).

\section{Activity 1: "Select the sample by clicking on it"}

Activity 2: Color description: "Is the color light or dark? The correct description activates a box that provides more information about colors and tones. If the answer is wrong, the student must start over. You cannot access activity 3 until activity 2 has been completed.

Activity 3 This activity asks the question: "Can you distinguish any crystal?" The student will choose the option that he considers correct. The correct option displays a new window with additional information about the crystallinity of the rock. The wrong answer will set you back. The student cannot access activity 4 until activity 3 has been completed.

Activity 4: In this activity, the student is asked: "Does this rock look like granite?" Granite is a very common rock, and most rock studies are based on comparing it to granite. The correct answer allows the student to access a more extensive explanation of this question. The wrong answer takes the student back to the beginning of this activity. Activity 5 cannot be accessed until Activity 4 has been completed. 


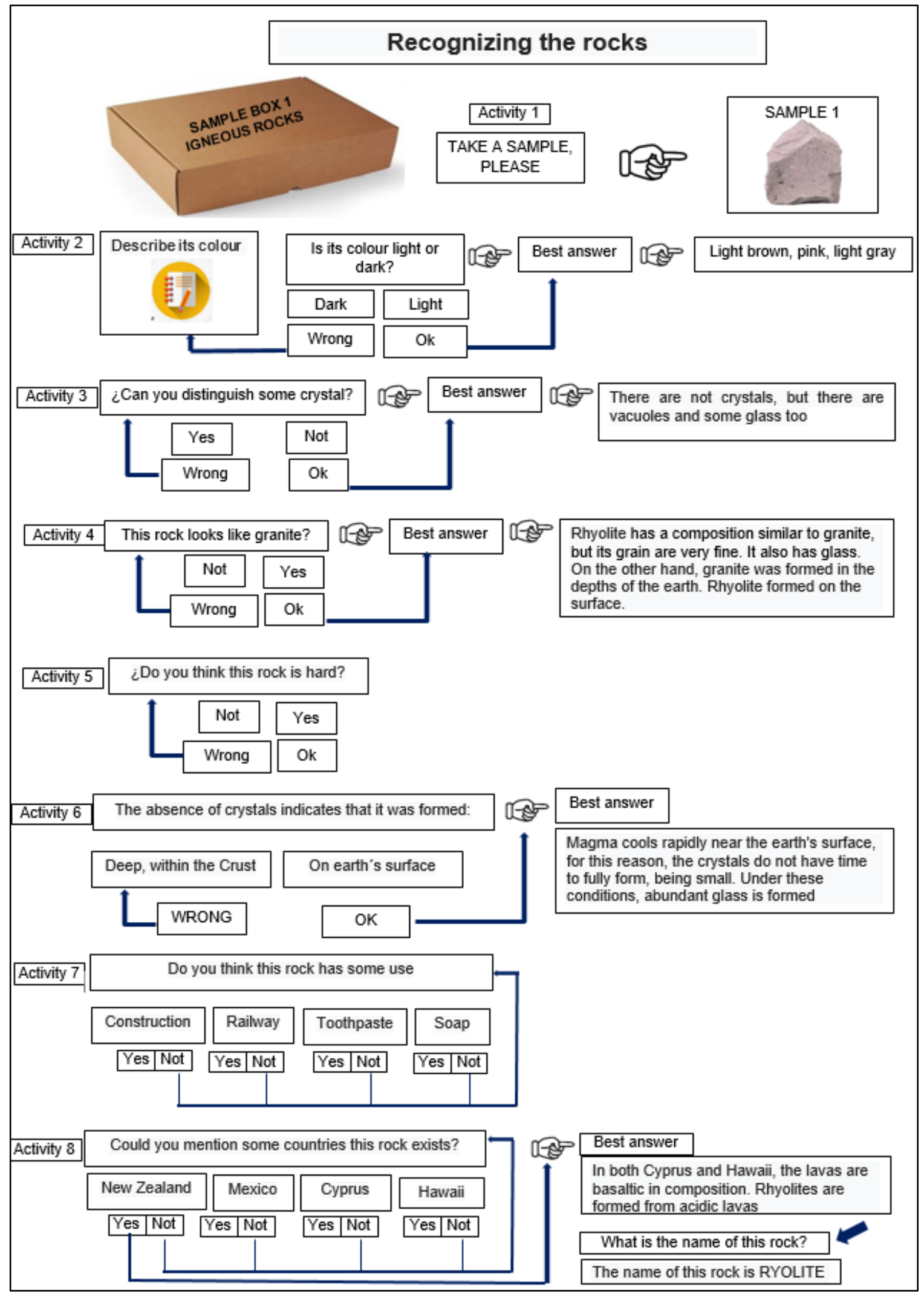

Figure 5. Proposed diagram for rocks recognition learning process for elementary school students. 
Activity 5: In this activity, the question is asked about the hardness of the rock: "Do you think this rock is hard?". The wrong choice leads to the start of this activity. The student cannot access Activity 6 until Activity 5 has been satisfactorily completed.

Activity 6: In this activity, the student must answer the following question: "The absence of crystals indicates that this rock was formed: Deep, within the Crust, or on Earth's surface". If the student answers correctly, he finds an option with more explanation on the questions raised. The wrong answer forces the student to return to the beginning of this activity. The student cannot access activity 7 until activity 6 has been satisfactorily completed.

Activity 7: In this activity, the student is asked: "Do you think this rock has any use?". Like in the case of minerals, there are four commands with different options, and each command has two additional subcommands with right and wrong answers. Choosing at least one wrong option sends the student to the first step of this activity. The right answers open access to activity 8.

Activity 8: This activity asks the student where the deposits of this type of rock can be found, through the following question: "Could you mention some countries where this rock exists?". Four commands are activated indicating four different countries. Two of these countries are wrong and the other two are right. Choosing the wrong countries sends the student to the beginning of the activity. The right answers give access to a screen with more information. At the same time, the student can access an area where he can identify the name of the rock.

Next, the student can click on a command that has the following label: "I WANT TO KNOW MORE ABOUT THE USE OF THIS ROCK" [27, 28,29], where he can learn, through examples of images, the uses and applications of the studied rock (see figure 6).

\section{WANT TO KNOW MORE ABOUT THE USE OF THIS ROCK}

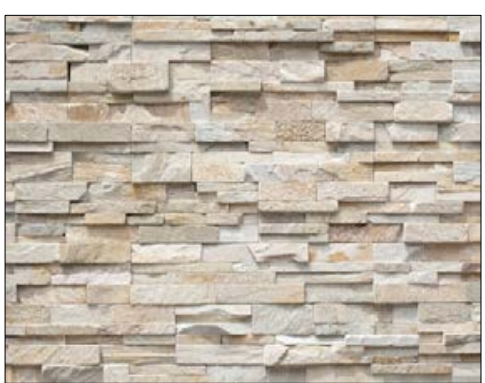

a

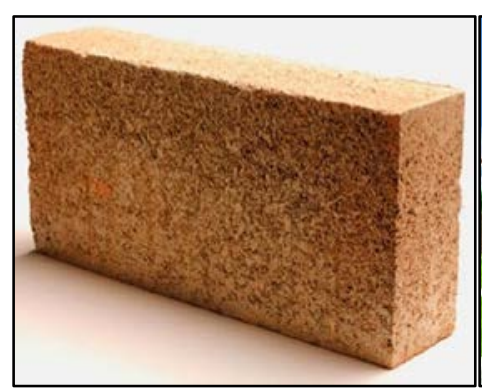

$b$

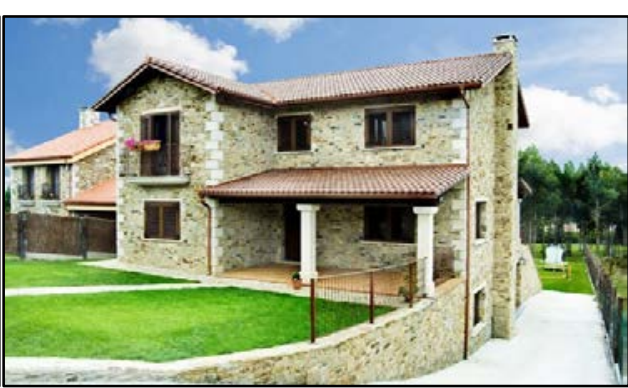

C

Figure 6. Graphic examples of the use and applications of rocks: a) natural rock [27]; b) blocks [28]; c) houses [29].

\section{RESULTS}

Although the development of these exercises is in the initial stages of implementation and dissemination, the most important achievement of this tool is that the student manages the entire process himself. As it is a complementary educational tool that is easy for teachers to use, a favorable reception is expected in the field of complementary school activities or even extracurricular activities.

\section{CONCLUSIONS}

The game consisting of different exercises and activities, proposed as an educational method, allows primary school students to be able to begin to recognize as many varieties of minerals and rocks as they wish. It also has the advantage that it can be accessed from any computer medium and from anywhere, and is also free. It is an innovative, fast, comfortable, interactive, and efficient learning system. 
The method can be adjusted to different levels of complexity, depending on the age of the student; that is, it can be aimed at students from primary school to university education.

\section{ACKNOWLEDGEMENTS}

Special recognition should be given to the EIT Raw Materials and also to the people who developed the Raw Materials Academy for funding this project and allowing developing it. We would also like to thank the different universities and institutions who decided to participate with the confidence of creating something really new.

\section{REFERENCES}

[1] García Laso, A. (2014). "Development of competencies in engineering education through participation in programs with social organizations. The case of the Unit of Social Entrepreneurship, Ethics and Values in Engineering". (Doctoral dissertation), Universidad Politécnica de Madrid - Technical University of Madrid.

[2] Martín, D. A., \& García-Laso, A. (2014). "Experiences in social innovation: a platform for ethics through a school of engineering studies". Journal of Cases on Information Technology, 16(3), 417. doi:10.4018/jcit.2014070102

[3] M. E. Sánchez, Y. Hernández, S. Hernández (2019). "Teaching innovation in human resources through service-learning. A pilot experience". RIDAS. Revista Iberoamericana de Aprendizaje Servicio, 7, 1-16.

[4] Service-Learning. (n.d.). Service-Learning. Teaching \& learning innovation. Retrieved from https://servicelearning.utk.edu/1705-2/

[5] Muñoz, E. (2015). A journey to the center of human evolution ethics revealed as a factor of evolution.

[6] Retrieved from https://www.institutoroche.es/biotecnologia/94/a

[7] D. A. Martín, A. García, J.L. Costafreda, D. Bolonio, L. Presa (2017). "The Monitor Project as a leveling strategy in the university". Universidad Politécnica de Madrid

[8] D.A.Martín, A. García, J.L. Costafreda Mustelier (2019). "Challenges in educational innovation: eco-social values in engineering education". Sistemas ; pp. 1-3. ISSN 0210-0223.

[9] D.A. Martín, A. García, J.L. Costafreda, J.L. Parra (2020). Chapter 2: Integrative Learning Toward Social Responsibility in Teaching Engineering: "Sustainable Development Goals: Quality Education". S. T. Handbook of Research on Operational Quality Assurance in Higher Education for Life-Long Learning. ISBN13: 9781799812395. DOI: 10.4018/978-1-7998-1238-8.ch002.

[10] P.P. Chamorro, B. Luque, A. Reina, D. García, D. Ojeda, C.De la Mata, M. Calderón, D. Gutiérrez, A. Antolí (2020). "Cooperative learning methodologies through Information and Communication Technologies (ICT)". Vol. 9 Núm. 2 (2020): Revista de Innovación y Buenas Prácticas Docentes. DOI: https://doi.org/10.21071/ripadoc.v9i2.12987.

[11] J.E. Ortiz, A.P. Perez, R. Castedo, M. Chiquito, D.A. Martín, J.L. Parra, J.L. Costafreda, J. Pous, I. Arribas, J.L. Sanz, I. Cañamón (2020). "Gamification to motivate and improve the learning of Geology". Virtual USATIC 2020 International Congress, 8-10 July 2020.

[12] M. Escribano, C.López Jimeno, C. Mataix (2019). Manual de minerales críticos y estratégicos en la nueva economía. Grupo de Proyectos de Ingeniería. ISBN: 978-84-96140-62-2.

[13] M.I. Carretero, M. Pozo (2007). "Applied Mineralogy. Health and Environment". Editorial Thomson. ISBN: 978-84-9732-487-8. 406 págs.

[14] European Commission. (2019). "The European Green Deal". Communication from the Commission to the European Parliament, the European Council, the Council, the European 
Economic, and Social Committee end the Committee of the Regions. Brussels. Retrieved from https://ec.europa.eu/info/sites/info/files/european-green-deal-communication_en.pdf

[15] BetterGeo (2018) "Teach about raw materials with Minecraft!". Retrieved from https://www.bettergeoedu.com/

[16] European Institute of Innovation \& Technology. EIT - Making innovation happen. Accessed 28 December 2018. Retrieved from https:// eit.europa.eu

[17] EIT Raw Materials. Developing Raw Materials into a major strength for Europe. Accessed 28 December 2018. Retrieved from https:// eit.europa.eu/eit-community/eit-raw-materials

[18] P. Westrin (2020) "Educational material about raw materials, circular economy \& sustainability supported by BetterGeoEdu". Retrieved from https://www.bettergeoedu.com/

[19] F. Vázquez (2012). "Mineral deposits handbook". UD proyectos. ISBN: 978-84-96140-41-7. 597 págs.

[20] L. Robb (2004). "Introduction to ore-forming processes". Ed. Blackwell Publishing. ISBN: 0-63206378-5. 386 págs.

[21] E. J.Tarbuck, F. K. Lutgens (2008). "Earth sciences. An Introduction to Physical Geology". $8^{\text {a }}$ edición. Pearson Education, Inc, Pages.712. ISBN: 0-13-114865-6

[22] https://es.wikipedia.org/wiki/Cobre. Accessed 28 December 2018.

[23] https://okdiario.com/economia/eliminar-monedas-centimo-aportara-cobre-suficiente-darelectricidad-230-000-hogares-781743. Accessed 10th January 2021.

[24] https://www.maelectricos.com/productos/cable-cobre-aislado-thhn-thwn-2-90degc-x-metroprocables-color-negro. Accessed 10th January 2021.

[25] https://es.123rf.com/photo_83785196_tuber\%C3\%ADa-tubos-de-cobre-con-varias-conexionesde-compresi\%C3\%B3n.html. Accessed 10th January 2021.

[26] http://edafologia.ugr.es/rocas/riolita.htm. Accessed 10th January 2021.

[27] https://pixers.es/vinilos/la-textura-de-las-paredes-de-piedra-66294015. Accessed 10th January 2021.

[28] https://www.amazon.com/-/es/Empire-Heavy-ladrillo-refractario-Brick/dp/B07234DDBK. Accessed 10th January 2021.

[29] https://www.pinterest.es/pin/862017184903432196/. Accessed 10th January 2021. 